1 Dahlöf B, Lindholm LH, Hansson L, Schersten B, Ekbom T, Wester PO, et al. Morbidity and mortality in the Swedish trial in old patients with hypertension (STOP-Hypertension). Lancet 1991;338:1281-5.

2 Amery A, Birkenhäger W, Brixko R, Bulpitt C, Clement D, Deruyttere M, et al. Efficacy of antihypertensive drug treatment according to age, sex, blood pressure and previous cardiovascular disease in patients over the blood pressure and previous car

3 SHEP Cooperative Research Group. Prevention of stroke by antihypertensive drug treatment in older persons with isolated systolic hypertension. JAMA 1991;265:3255-64.

4 Kostis JB, Davis BR, Cutler J, Grimm RH, Berge KG, Cohen JD, et al. Prevention of heart failure by antihypertensive drug treatment in older persons with isolated systolic hypertension. JAMA 1997;278:212-6.

5 Holme I, Waaler HT. Five-year mortality in the city of Bergen, Norway, according to age, sex and blood pressure. Acta Med Scand 1976;200:22939.

6 Heikinheimo RJ, Haavisto MV, Kaarela RH, Kanto AJ, Koivinen MJ, Rajala SA. Blood pressure in the very old. J Hypertens 1990;8:363-7.

7 Rajala S, Haavisto M, Heikinheimo R, Mattila K. Blood pressure and mortality in the very old. Lancet 1983;ii:520-1.

8 Mattila K. Haavisto M, Rajala S, Heikinheimo R. Blood pressure and five year survival in the very old. $B M J 1988: 296: 887-9$

9 Langer RD, Ganiats TG, Barret-Connor EL. Factors associated with paradoxical survival at higher blood pressure in the very old. Am J Epidemiol 1991;134:29-38
10 Izaks GJ, van Houwelingen HC, Schreuder GM, Ligthart GJ. The association between human leucocyte antigens (HLA) and mortality in community residents aged 85 and older. J Am Geriatr Soc 1997;45:56-60.

11 Lagaay AM, van der Meij JC, Hijmans W. Validation of medical history taking as part of a population based survey in subjects aged 85 and over. BMJ 1992;304:1091-2.

12 Folstein MF, Folstein SE, McHugh PR. "Mini-mental state": a practical method for grading the cognitive state of patients for the clinician. J Psychiatr Res 1975;12:189-98.

13 Weverling-Rijsburger AWE, Blauw GJ, Lagaay AM, Knook DL, Meiders $\mathrm{AE}$, Westendorp RGJ. Total cholesterol and risk of mortality in the oldest old. Lancet 1997;350:1119-23.

14 Ligthart GJ, Corberand JX, Fournier C, Galanaud P, Hijmans W, Kennes B, et al. Admission criteria for immunogerontological studies in man: the SENIEUR protocol. Mech Ageing Dev 1984;28:47-55.

15 Guo Z, Viitanen M, Winblad B. Low blood pressure and five-year mortality in a Stockholm cohort of the very old: possible confounding by cognitive impairment and other factors. Am J Public Health 1997;87:623-8.

16 Glynn RJ, Field TS, Rosner B, Hebert PR, Taylor JO, Hennekens CH. Evidence for a positive linear relation between blood pressure and mortality in elderly people. Lancet 1995;345:825-9.

(Accepted 12 February 1998)

\title{
Lone atrial fibrillation in vigorously exercising middle aged men: case-control study
}

Jouko Karjalainen, Urho M Kujala, Jaakko Kaprio, Seppo Sarna, Matti Viitasalo

Central Military Hospital, Box 50 00301 Helsinki, Finland

Jouko Karjalainen, internist

continued over BMJ 1998;316:1784-5

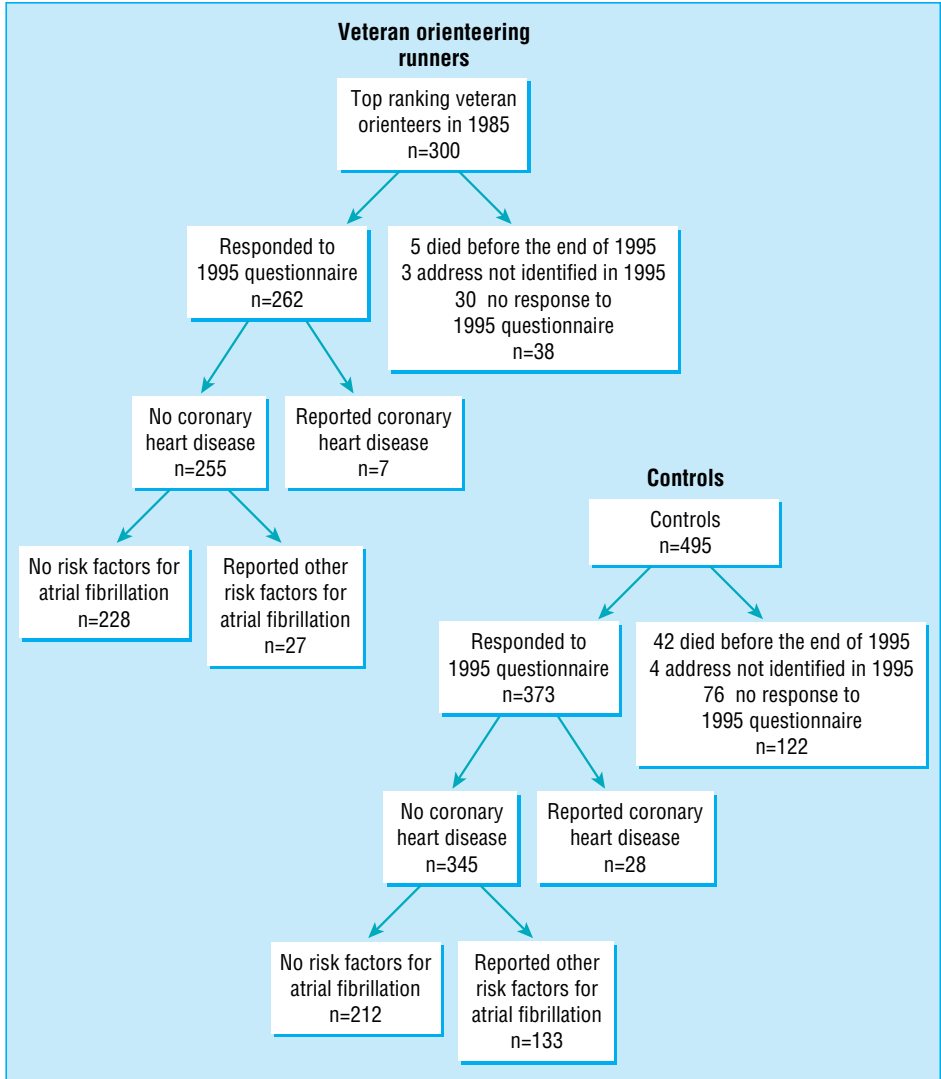

Flow chart of study. Other risk factors for atrial fibrillation were hypertension, myocardial or valve disease, diabetes, thyroid disorder, and severe obesity endurance sports. We therefore compared the prevalence of atrial fibrillation in middle aged men doing intense endurance training and men from the general population.

\section{Subjects, methods, and results}

We chose top level veteran orienteers to represent subjects doing long term vigorous exercise. A high position in the veteran ranking list is an indicator of years of intense training. We enrolled the 60 top ranked orienteers in 1984 from the race classes age 35-39 years, $40-44$ years, $45-49$ years, and $55-59$ years, a total of 300 runners. The 495 controls comprised all men aged 35-59 enrolled for an earlier study. ${ }^{2}$ At 20 years old these subjects had been completely healthy (fully fit for military service). Mean (SD) age at baseline was 47.5 (7.0) years in orienteers and $49.6(5.3)$ years in controls. Controls had responded in 1985 to a questionnaire which included items on physical activity and occurrence of various diseases. ${ }^{2}$

In 1995 we sent a similar questionnaire to the orienteers and controls but which contained an additional question on cardiac arrhythmias: "Has a doctor ever told you that you have atrial fibrillation or atrial flutter." Those who answered "yes" completed another detailed questionnaire on atrial fibrillation, and electrocardiograms and other data were obtained from their medical records to confirm the diagnosis. We excluded all subjects who reported known risk factors for atrial fibrillation. $^{3}$

Ninety per cent (262) of the orienteers and 83\% (373) of the controls responded to the questionnaire (figure). Compared with the general population orienteers had much lower mortality (1.7\% (95\% confidence interval 0.5 to $3.8 \%)$ v $8.5 \%(6.2 \%$ to $11.3 \%))$, lower reported coronary heart disease since 1985 (2.7\% (1.1 to $5.4 \%)$ v $7.5 \%(5.1 \%$ to $10.7 \%))$, and fewer risk factors for atrial fibrillation (figure). However, in men without known risk factors, lone atrial fibrillation had been 
diagnosed in 12 of $228 \quad(5.3 \% \quad(2.8 \%$ to $9.0 \%))$ orienteers and in 2 of $212(0.9 \%(0.1 \%$ to $3.4 \%))$ controls $(\mathrm{P}=0.012$, two tailed Fisher's exact test), the relative risk being 5.5 (1.3 to 24.4 ) in orienteers. The two controls with lone atrial fibrillation also took vigorous exercise. The age-specific prevalence of lone atrial fibrillation at the end of 1995 in orienteers was $4.2 \%$ (4/95) for those aged 46-54 years, $5.6 \%$ (4/72) for those aged $55-62$ years, and $6.6 \%(4 / 61)$ for those aged 63-70 years. In subjects with risk factors atrial fibrillation had been diagnosed in 12\% (4/34) of orienteers and $9 \%(15 / 161)$ of controls $(\mathrm{P}>0.05)$.

The first attack of lone atrial fibrillation in orienteers was at a mean age of 52 years (SD 10, range 34 to 68 ) after an average training history of 36 years. Three also had documented episodes of atrial flutter.

\section{Comment}

Vigorous long term exercise is associated with atrial fibrillation in healthy middle aged men despite protecting against coronary heart disease and premature death. In population studies the average prevalence of atrial fibrillation, persistent or paroxysmal, is $0.5 \%$ in subjects aged $45-54$ years, about $1 \%$ at $55-64$ years, and $4 \%$ at $65-74$ years. ${ }^{4}$ The prevalences of lone atrial fibrillation in our sportsmen were higher.

The reasons for the increased risk of atrial arrhythmias in middle aged endurance athletes can only be speculated. Enhanced vagal tone, characteristic of endurance athletes, predisposes normal hearts to atrial fibrillation. $^{5}$ Atrial enlargement and left ventricular hypertrophy, both features of the endurance athlete's heart, may further increase the tendency to atrial fibrillation. We do not know whether stopping exercise would have prevented recurrence of atrial fibrillation. Most of the orienteers with commonly relapsing cases had responded adequately to antiarrhythmic drugs and continued competing.

Contributors: JK had the idea for the study and overal responsibility for interpreting the data and preparing the manuscript. UMK designed the study and collected the data. JK and SS collected and analysed the data. MV interpreted the data All authors contributed to writing the paper. JK and UMK are the guarantors.

Funding: Finnish Defence Forces.

Conflict of interest: None.

1 Morris JN, Everitt MG, Pollard R, Chave SPW. Vigorous exercise in leisure-time: protection against coronary heart disease. Lancet 1980;ii:1207-10.

2 Kujala UM, Kaprio J, Taimela S, Sarna S. Prevalence of diabetes, hypertension and ischemic heart disease in former elite athletes. Metabolism 1994;43:1255-60.

3 Krahn AD, Manfreda J, Tate RB, Mathewson F, Cuddy TE. The natura history of atrial fibrillation: incidence, risk factors, and prognosis in the Manitoba follow-up study. Am J Med 1995;98:476-84.

4 Feinberg WM, Blackshear JL, Laupacis A, Kronmal R, Hart RG. Prevalence, age distribution and gender of patients with atrial fibrillation. Arch Intern Med 1995;155:469-73.

5 Coumel P. Paroxysmal atrial fibrillation: a disorder of autonomic tone? Eur Heart J 1994;15(suppl A):9-16. (Accepted 27 October 1997)
Unit for Sports and Exercise Medicine, Institute of Biomedicine, University of Helsinki, 00250 Helsinki

Urho M Kujala, chief physician

Department of Public Health, University of Helsinki, 00290 Helsinki

Jaakko Kaprio, senior researcher Seppo Sarna, associate professor First Department of Medicine, Helsinki University Hospital, 00290 Helsinki

Matti Viitasalo, cardiologist

Correspondence to: Dr J Karjalainen jouko.karjalainen@ pp.inet.fi

\section{Memorable patients \\ Down but not out}

A decade ago my first house officer posting was in a paediatric ward in a Malaysian general hospital. One of my patients was a 2 year old Malay boy with Down's syndrome who had been referred for hypercyanotic spells. He was a scrawny looking kid with the deepest cyanosis I had ever seen. What made him stand out in the busy paediatric ward was his sunny smile for everyone who passed his cot. He had been referred 12 months earlier for cyanotic spells and when Tetralogy of Fallot was diagnosed he was sent home to a rural village to await a date for palliative surgical treatment. I discovered much later that the number of names on the paediatric cardiac surgery list was longer than anyone could count and children with major birth defects and Down's syndrome inevitably had low priority.

That evening, he had an episode of hypercyanotic spell. I curled him up into a knee chest position, gave oxygen by a face mask, and held his hand while my senior medical officer gave him the maximum doses of intravenous sodium bicarbonate, propranolol, and morphine. His mother, apparently used to this sight now, stood stoically by, holding his other hand, and prayed. The same scene was repeated again the next night, but each morning he would recover well enough to give the ward staff his usual wide grin, and cheerfully allow himself to be examined. The third morning I noted that his cot was empty; he had died in the early hours. I peered into the waiting room and met the mother's eyes. I sat next to her, and not knowing what to say I kept silent. She gazed at me, smiled weakly, and whispered, "Thank you" before leaving. Anger welled inside me and I felt ashamed of my profession. Throughout my early years in paediatric training I was haunted by the thought that medical knowledge without adequate resources would not save a child's life.

Three years ago, as a newly appointed paediatric lecturer in an oncology ward, my house officer presented a baby girl with
Down's syndrome and acute myeloid leukaemia. Sadly, the day before it was confirmed that she had had an early relapse of her leukaemia even while having chemotherapy. I turned to the patient and saw the friendliest smile in the ward. I then turned to her parents and began to give them the guarded prognosis and explain the need to change the chemotherapy regimen. They listened silently to my explanation. Then the father spoke in a quiet but determined voice, "We are taking our baby home today." His wife pleaded, "No more injections, please." Two weeks later, my patient celebrated her 1st birthday and died in her mother's arms at home.

I have now learnt two lessons from my young patients with Down's syndrome and their families. Firstly, never abandon your patients even when working under conditions of great adversity and limited resources. Secondly, even with all the resources in the world, know when to stop treatment. I believe that parents are usually the best people to know and to decide on this. To do any less may be to miss an opportunity to act in the best interest of the child.

\section{K Thong, lecturer in paediatrics, University of Malaya, Malaysia}

We welcome articles up to 600 words on topics such as A memorable patient, A paper that changed my practice, My most unfortunate mistake, or any other piece conveying instruction, pathos, or humour. If possible the article should be supplied on a disk. Permission is needed from the patient or a relative if an identifiable patient is referred to. We also welcome contributions for "Endpieces," consisting of quotations of up to 80 words (but most are considerably shorter) from any source, ancient or modern, which have appealed to the reader. 